\title{
Smoking and Pancreatic Disease
}

\author{
Mouad Edderkaoui ${ }^{1 *}$, Edwin Thrower ${ }^{2}$ \\ ${ }^{1}$ Cedars-Sinai Medical Center \& University of California, Los Angeles, USA; ${ }^{2}$ Yale University \& VA CT Healthcare, New Haven, \\ USA. \\ Email: *mouad.edderkaoui@cshs.org
}

Received October $4^{\text {th }}, 2013$; revised November $1^{\text {st }}, 2013$; accepted November $8^{\text {th }}, 2013$

Copyright (C) 2013 Mouad Edderkaoui, Edwin Thrower. This is an open access article distributed under the Creative Commons Attribution License, which permits unrestricted use, distribution, and reproduction in any medium, provided the original work is properly cited.

\begin{abstract}
Smoking is a major risk factor for chronic pancreatitis and pancreatic cancer. However, the mechanisms through which it causes the diseases remain unknown. In the present manuscript we reviewed the latest knowledge gained on the effect of cigarette smoke and smoking compounds on cell signaling pathways mediating both diseases. We also reviewed the effect of smoking on the pancreatic cell microenvironment including inflammatory cells and stellate cells.
\end{abstract}

Keywords: Smoking; Pancreatitis; Pancreatic Cancer

\section{Introduction}

Numerous studies have shown that cigarette smoking increases the risk of developing pancreatic cancer, although its contribution to pancreatitis has only been appreciated in recent years [1-3]. Clinical advances have identified a role for cigarette smoke in pancreatitis, but experimental data regarding its disease mechanism are scarce. In this review, advances in basic science research are summarized, regarding the role of cigarette smoke, and it's most potent constituents, in pancreatitis and pancreatic cancer.

\section{Factors Involved in Smoking-Related Pancreatic Disease}

Of the 4000 chemicals in cigarette smoke, greater than 60 have been identified as prospective carcinogens. Tobacco smoke and its various components, including nicotine, 4-(methylnitrosamino)-1-(3-pyridyl)-1-butanone (NNK), and other tobacco specific nitrosamines have been studied in cells and in vivo [4-11]. In laboratory animals, the most potent nicotine metabolite is NNK [12]. Other nitrosamines formed from nicotine include N'-nitrosonornicotine (NNN) and Diethylnitrosamine [13]. These nicotine metabolites are potentially formed via nitrosation during processing of the tobacco plant [14]. It has been reported that roughly $46 \%$ of NNN and $26 \%-37 \%$ of $\mathrm{NNK}$ in tobacco are preformed and the remainder is py-

\footnotetext{
${ }^{*}$ Corresponding author.
}

rosynthesized from nicotine during smoking [15]. Of these constituents, nicotine and NNK are the most studied constituents with respect to pancreatic disease. Other potentially harmful components of tobacco smoke include polycyclic aromatic hydrocarbons, although their role in pancreatic disease is undetermined $[15,16]$.

Few reliable animal models of smoking and pancreatic disease have been developed, and little is known about underlying cellular mechanisms. Those that have been established involve exposure of rodents to cigarette smoke in specialized smoke-delivery chambers, or ingestion/injection of a tobacco toxin over a period of time. The subsequent sections will focus on some of these models and underscore the latest developments in our understanding of smoking-related pancreatitis and pancreatic cancer.

\section{Smoking and Pancreatitis}

\subsection{Cigarette Smoke Exposure and Pancreatitis}

In models of cigarette smoke exposure over a period of weeks rats developed pancreatic damage, elevated pancreatic levels of the digestive zymogens, trypsinogen and chymotrypsinogen, [5] and altered gene expression, affecting the ratio of trypsinogen to its endogenous inhibitor (pancreas-specific trypsin inhibitor; PSTI). Smokeexposed animals had increased susceptibility to pancreatitis as a result of these changes [7]. Given that smoking exacerbates the clinical effects of alcohol in pan- 
creatitis, one model combined smoke treatment with ethanol consumption; pancreatic ischemia worsened and increased leukocyte infiltration was seen [9].

While these studies are informative, they only describe effects of smoke; they do not identify relevant toxins or how they initiate these cellular effects. The studies detailed in subsequent sections focus on nicotine and its potent metabolite $\mathrm{NNK}$, revealing a role for these nitrosamines and potential pathways underlying disease initiation.

\subsection{Nicotine and NNK-Mediated Pathways in Pancreatitis}

Nicotine is a key toxin in tobacco and cigarettes and may contribute to the development of pancreatitis and pancreatic cancer. Nicotine is swiftly absorbed in the lungs and is eliminated from the body within 120 - 180 minutes [17]. Metabolism of nicotine primarily occurs via the cytochrome P450 (CYP) 2A6 pathway along with other enzymes including aldehyde oxidase 1, UDP-glucuronosyltranferases, flavin-containing monooxygenase 3 and other CYPs e.g. 2A13, 2B6. Polymorphisms in CYP2A6 have been related to racial and genetic variations in nicotine metabolism, but it is unknown if these contribute to smoking-related pancreatic disease [18]. Moreover, elevated P450 enzyme levels have been reported in patients with chronic pancreatitis and pancreatic cancer as compared to healthy controls [19]. Rats exposed to ${ }^{3} \mathrm{H}-$ nicotine saw a noticeable buildup of it in the pancreas and intestine $[19,20]$. Further, metabolites of nicotine were detected in samples of human pancreatic juice from smokers. Cotinine, the primary nicotine metabolite, was present at levels of $129+/-156 \mathrm{ng} / \mathrm{ml}$ followed by NNK at $1.37 \mathrm{ng} / \mathrm{ml}$ to $600 \mathrm{ng} / \mathrm{ml}(0.7 \mu \mathrm{M}$ and $6.6 \mathrm{nM}-3 \mu \mathrm{M}$ respectively) [21]. These levels of nicotine metabolites may be sufficient to activate cell surface receptors on the exocrine pancreas that could mediate pancreatitis and pancreatic cancer responses.

Studies have been undertaken to ascertain the pathological and functional effects of nicotine on the pancreas. In several studies, nicotine exposure resulted in cytoplasmic swelling, vacuolization, pyknotic nuclei and karyorrhexis, which were localized to the exocrine pancreas. Furthermore, a decreased secretory response was observed. along with increased retention of pancreatic pro-enzymes [4,22-29]. A recent study has shown that secretory effects induced by nicotine in isolated rat acini were abrogated following treatment with a nicotinic receptor antagonist and calcium channel antagonists [28]. These findings indicate that nicotine effects are mediated via a nicotinic acetylcholine receptor (nAChR) and calcium is the resultant signaling pathway. Nicotine also has been shown to alter basal levels of GI hormones (gastrin; $\mathrm{CCK}$ ) and serum enzymes such as amylase and lipase in blood circulation in rats [24]. Such changes have been linked to morphological changes observed during pancreatitis $[19,27]$. Nicotine has also been shown to modulate oxidative stress and lipid peroxidation although it is unclear if these processes participate in the pathophysiology of acute and chronic pancreatitis [29].

The nicotine metabolite, NNK, is one of the most abundant and injurious tobacco-specific carcinogens. It is a high-affinity agonist of nicotinic acetylcholine receptors (nAChR) and may affect the development of pancreatic cancer through receptor-mediated pathways $[10,13]$. These receptors were first characterized within the nervous system, but have since been shown to be present in non-neuronal cells [13]. Cancer cell lines as well as human keratinocytes and epithelial cells has been shown to have $\alpha 7 \mathrm{nAChR}$ and respond to NNK (EC50 for NNK = $0.03 \mu \mathrm{M})$. Although nicotine is $5000-10000$ times more concentrated in tobacco smoke than NNK and 2000 3000 times more concentrated than NNN, NNK shows 1000 -fold higher affinity for $\alpha 7 \mathrm{nAChR}$ compared to nicotine. Additionally, $\alpha 7 \mathrm{nAchRs}$ are up-regulated in the organs of smokers, and experimentally in the pancreas and lungs of rodents following chronic nicotine/NNK exposure $[8,13]$.

The role of NNK as an initiator of acute pancreatitis in rats was described recently by Alexandre et al., [30]. Using isolated acinar cells and in vivo models of pancreatitis, they demonstrated that NNK induced premature activation of digestive zymogens (trypsinogen and chymotrypsinogen), a pivotal event in initiating pancreatitis. Cerulein (an orthologue of the hormone cholecystokinin; CCK) is commonly used in isolated pancreatic acinar cells or animals in supraphysiologic concentrations (10 $100 \mathrm{x}$ that required to induce physiological responses), to cause experimental pancreatitis. NNK treatment in a cerulein model of the disease elevated zymogen activation above that seen with NNK or cerulein treatment alone. Furthermore, NNK triggered cellular damage in the pancreas (vacuolization, pyknotic nuclei, and edema) consistent with that observed during acute pancreatitis. The NNK receptor target, $\alpha-7 \mathrm{nAChR}$, was detected in rat acini by PCR analysis. In addition, NNK mediated zymogen activation was completely abrogated when isolated acini were pre-treated with mecamylamine (a $\mathrm{nAChR}$ blocker), validating a key role for $\alpha-7 \mathrm{nAChR}$ in triggering smoking-related pancreatitis. These findings are the first to identify direct effects of cigarette toxins on the acinar cell through a receptor-mediated mechanism.

NNK may also stimulate pancreatitis responses via $\beta$-adrenergic receptors. NNK is structurally similar to classic $\beta$-adrenergic agonists and has high affinity for human $\beta$-1 and $\beta$-2 receptors, with a preference for $\beta-1$ $\left(\mathrm{EC}_{50}\right.$ for $\beta 1=5.8 \mathrm{nM} ; \mathrm{EC}_{50}$ for $\left.\beta 2=128 \mathrm{nM}\right)$ [31]. Activation of $\beta$-adrenergic receptors results in activation of 
adenylate cyclase, generation of cAMP, or release of arachidonic acid. Elevations in cAMP have been implicated in pancreatitis responses [32]. The enzyme phospholipase A2 (PLA2) mediates arachidonic acid release which is an important facilitator of inflammation; isoforms of phospholipase A2-II and A2-IV are elevated during human acute pancreatitis and may contribute to inflammatory effects through this pathway [33]. One study identified $\beta-1$ and $\beta$-2 adrenergic receptors in rat acini by PCR analysis, however the $\beta$-adrenergic receptor blocker propranolol did not prevent NNK-mediated zymogen activation in isolated acini [30].

Whether NNK potentiates additional pancreatitis responses through nicotinic, $\beta$-adrenergic, or other receptors remains a focus for future research.

\subsection{Regulation of Inflammation by Smoke Compounds in Pancreatitis}

NNK and nicotine may exert influence over inflammatory cells during pancreatitis by binding to $\alpha 7 \mathrm{nAChR}$ expressed on macrophages, thereby modulating immune responses. Nicotine blocks production of pro-inflammatory cytokines from macrophages by inhibiting the NF $\kappa \mathrm{B}$ pathway, which is involved in macrophage activation $[24,35]$. Furthermore, treatment of mice with mecamylamine ( $\alpha 7 \mathrm{nAChR}$ blocker) decreased neutrophil and macrophage migration to pancreatic tissue and intensified severity of experimental pancreatitis [36]. Prolonged exposure to cigarette smoke, however, results in chronic inflammation in the pancreas, indicating that an antiinflammatory effect may be a short term response that gives way to a chronic inflammatory phase [37]. Proinflammatory effects of NNK may be a result of its uptake and metabolism by macrophages. In U937 human macrophages NNK was metabolized and subsequently it activated $\mathrm{NF} \kappa \mathrm{B}$, causing $\mathrm{TNF} \alpha$ release which promotes inflammation [10]. Therefore, NNK and other tobacco derived nitrosamines likely mediate early pancreatitis events through interaction with $\alpha 7 \mathrm{nAChR}$ on acini and macrophages; chronic-inflammatory responses occur much later, perhaps through uptake and metabolism of such compounds.

\section{Smoking and Pancreatic Cancer}

Tobacco smoking is a major established risk factor for pancreatic cancer $[21,38]$. It increases the risk of pancreatic cancer up to 6-fold depending on the duration and intensity of smoking [39-41]. Nearly one quarter of all pancreatic cancer deaths are linked to tobacco use [42]. Two different studies published recently showed that smokers are diagnosed with pancreatic cancer at ages 8 to 15 years younger than non-smokers $[43,44]$. Therefore, understanding the mechanisms through which smoking predisposes to pancreatic cancer is urgently needed. This will help target patients at high risk for the disease with preventive strategies, and permit development of treatment approaches directed at cell signaling pathways involved in smoking-induced pancreatic cancer.

\subsection{Cigarette Smoke-Mediated Pathways in Pancreatic Cancer}

As in chronic pancreatitis, slight progress has been achieved in understanding the signaling pathways regulated by cigarette smoke compounds in pancreatic cancer in recent years.

A major mechanism through which smoking compounds predispose to cancer in general is through inducing DNA adducts leading to genetic mutations. However, analysis of the pancreatic tissue did not show any association between increased level of mutations of pancreatic cancer-associated genes such as K-ras and p53 and smoking $[45,46]$. However, the same study found association between increases in less common mutations in pancreatic cancer patients and smoking status suggesting possible role of these mutations in mediating the smoking pro-cancer effect in the pancreas [46].

As discussed earlier, major cigarette smoke carcinogen NNK interacts with pancreatic cells through $\beta$-adrenergic receptor and $\mathrm{nAChR}[6,47-49]$. These receptors mediate NNK activation of Cox2, EGFR and Erk in pancreatic cancer cells and ductal cells $[47,48]$. These pathways regulate proliferation and cell death in pancreatic cells.

We showed that NNK and cigarette smoke extract stimulate proliferation and inhibit apoptosis of normal pancreatic ductal cells through a mechanism that involves Akt and AMP kinases [50]. In pancreatic cancer cells nicotine stimulates proliferation and invasion of the AsPC1 pancreatic cancer cell line. Furthermore, nicotine stimulates epithelial to mesenchymal transition (EMT) by down-regulating E-cadherin and $\beta$-catenin and upregulating vimentin and fibronectin in several cancer cells [51]. EMT has been associated with acquiring cancer stem cells characteristics suggesting regulation of pancreatic cancer stemness and resistance to treatment by smoking compounds.

In fact, recent data indicate that nicotine stimulates growth, invasion, and resistance of pancreatic cancer cells to chemotherapy through a mechanism that involves Src pathways and the inhibitor of differentiation-1 (Id1) transcription factor [52]. These effects were mediated by the $\alpha 7 \mathrm{nAChR}$ receptor.

Regulation of EMT/invasion/metastasis pathways and resistance to chemotherapeutic agents is extremely important to understand as these are the major contributors to the aggressiveness of pancreatic cancer. The data published in the last few years suggest that smoking compounds do not only contribute to the initiation of cancer, but also to the progression and the transformation of the 
cancer cells making them more metastatic and resistant to drugs. EMT and stemness pathways regulated by smoking compounds need to be further investigated.

\subsection{Cigarette Smoke and Regulation of the Microenvironment of the Pancreatic Tumors}

Pancreatic cancer is characterized by a strong desmoplastic reaction that includes inflammatory cells infiltration and fibrosis. There is increasing awareness of the role of the tumor microenvironment in progression of the disease.

Smoking compounds can worsen chronic pancreatitis leading to pancreatic cancer [53]. Fibrosis and inflammation are major characteristics of chronic pancreatitis. Exposure to cigarette smoke stimulates both fibrosis and inflammation in the pancreas of rats [54].

Extracellular matrix proteins (ECM) secretion leading to fibrosis is mainly mediated by activated pancreatic stellate cells. These cells have been shown to express nicotinic acetylcholine receptors and respond to nicotine exposure by increased proliferation and ECM production [55]. ECM production contributes to pancreatic cancer cell survival and resistance to apoptosis [56].

Differently from the effect of smoking on inflammation in chronic pancreatitis [30,33], very little is known about how inflammatory response would mediate smoking-induced pancreatic cancer.

NNK treatment has been shown to significantly increase macrophage infiltration and expression of proinflammatory mediators such as macrophage inflammatory protein 1 alpha (MIP-1 $\alpha$ ), interleukin 1 beta (IL-1 $\beta)$, and transforming growth factor-beta (TGF- $\beta$ ) in mice neoplastic lesions [5]. Macrophage and mast cell infiltration is observed in human pancreatic cancer as well [57].

Recent data showed that cigarette smoke extract significantly stimulated pancreatic ductal epithelial flattening and induced severe acini atrophy in Elastase-IL-1 $\beta$ transgenic mice. Cigarette smoke extract stimulated proliferation and inhibited apoptosis in pancreatic ductal epithelial cells in this model. Furthermore, analysis of the cell signaling pathways showed induction of COX-2 in the setting of chronic inflammation. A very recent paper showed that high fat diet activates oncogenic Kras via COX2 leading to pancreatic inflammation and fibrosis, and development of pancreatic intraepithelial neoplasia lesions and pancreatic ductal adenocarcinoma [58].

\subsection{Future Directions}

The lack of good animal models to study pancreatic cancer contributed to the slow progress in understanding how smoking causes the disease. Previous studies using hamsters and rats showed pro-cancer effect of the smoking compounds but only after very long time ( 1 to 2 years)
[12,59]. More recent animal models combining cigarette smoke compounds with carcinogenic chemicals such as 7,12-dimethylbenzanthracene (DMBA) or using orthotopic model of pancreatic cancer showed faster progression of the disease [59,60]. Developing mouse models of pancreatic cancer based on K-ras mice is greatly required and will serve as a useful tool in understanding the disease. These models will provide a good base to study the interaction between immune cells, stellate cells and pancreatic cancer cells in early and late stage of the disease.

\section{Conclusion}

The last few years have seen slow progress in understanding the effect of cigarette smoking on pancreatic disease. Smoking is a risk factor for acute and chronic pancreatitis, and pancreatic cancer. It also increases the risk of pancreatic cancer in patients with pancreatitis. Identification of cellular targets, such as nAChR, will help in development of potential therapies. Furthermore, the use of reliable animal models such as the Pdx1-Cre, LSL-Kras mice will help dissect relevant cellular changes in the pancreas induced by smoking.

\section{REFERENCES}

[1] J. S. Tolstrup, L. Kristiansen, U. Becker, et al., "Smoking and Risk of Acute and Chronic Pancreatitis among Women and Men: A Population-Based Cohort Study," Archives of Internal Medicine, Vol. 169, No. 6, 2009, pp. 603-609. http://dx.doi.org/10.1001/archinternmed.2008.601

[2] D. Yadav, R. H. Hawes, R. E. Brand, et al., Alcohol Consumption, Cigarette Smoking, and the Risk of Recurrent Acute and Chronic Pancreatitis," Archives of Internal Medicine, Vol. 169, No. 11, 2009, pp. 1035-1045. http://dx.doi.org/10.1001/archinternmed.2009.125

[3] O. Sadr-Azodi, A. Andren-Sandberg, N. Orsini and A. Wolk, "Cigarette Smoking, Smoking Cessation and Acute Pancreatitis: A Prospective Population-Based Study," Gut, Vol. 61, No. 2, 2012, pp. 262-267.

[4] P. Chowdhury, "An Exploratory Study on the Development of an Animal Model of Acute Pancreatitis Following Nicotine Exposure," Tobacco Induced Diseases, Vol. 1, 2003, pp. 213-217. http://dx.doi.org/10.1186/1617-9625-1-3-213

[5] U. A. Wittel, K. K. Pandey, M. Andrianifahanana, et al., "Chronic Pancreatic Inflammation Induced by Environmental Tobacco Smoke Inhalation in Rats," The American Journal of Gastroenterology, Vol. 101, No. 1, 2006, pp. 148-159.

http://dx.doi.org/10.1111/j.1572-0241.2006.00405.x

[6] M. D. Askari, M. S. Tsao, M. Cekanova, et al., "Ethanol and the Tobacco-Specific Carcinogen, NNK, Contribute to Signaling in Immortalized Human Pancreatic Duct Epithelial Cells," Pancreas, Vol. 33, No. 1, 2006, pp. 53- 
62. http://dx.doi.org/10.1097/01.mpa.0000226883.55828.e9

[7] U. A. Wittel, A. P. Singh, B. J. Henley, et al., "Cigarette Smoke-Induced Differential Expression of the Genes Involved in Exocrine Function of the Rat Pancreas," Pancreas, Vol. 33, 2006, pp. 364-370.

http://dx.doi.org/10.1097/01.mpa.0000240601.80570.31

[8] H. A. Al-Wadei and H. M. Schuller, "Nicotinic Receptor-Associated Modulation of Stimulatory and Inhibitory Neurotransmitters in NNK-Induced Adenocarcinoma of the Lungs and Pancreas," The Journal of Pathology, Vol. 218, No. 4, 2009, pp. 437-445. http://dx.doi.org/10.1002/path.2542

[9] W. Hartwig, J. Werner, E. Ryschich, et al., "Cigarette Smoke Enhances Ethanol-Induced Pancreatic Injury," Pancreas, Vol. 21, No. 3, 2000, pp. 272-278. http://dx.doi.org/10.1097/00006676-200010000-00009

[10] N. Rioux and A. Castonguay, "4-(Methylnitrosamino)-1(3-Pyridyl)-1-Butanone Modulation of Cytokine Release in U937 Human Macrophages," Cancer Immunology, Immunotherapy, Vol. 49, 2001, pp. 663-670. http://dx.doi.org/10.1007/s002620000157

[11] N. Trushin, G. Leder, K. El-Bayoumy, et al., "The Tobacco Carcinogen NNK is Stereoselectively Reduced by Human Pancreatic Microsomes and Cytosols," Langenbeck's Archives of Surgery, Vol. 393, No. 4, 2008, pp. 571-579. http://dx.doi.org/10.1007/s00423-007-0265-3

[12] A. Rivenson, D. Hoffmann, B. Prokopczyk, et al., "Induction of Lung and Exocrine Pancreas Tumors in F344 Rats by Tobacco-Specific and Areca-Derived N-Ni-trosamines," Cancer Research, Vol. 48, No. 23, 1988, pp. 6912-6917.

[13] H. M. Schuller, "Nitrosamines as Nicotinic Receptor Ligands," Life Sciences, Vol. 80, No. 24-25, 2007, pp. 2274-2280.

http://dx.doi.org/10.1016/j.lfs.2007.03.006

[14] S. S. Hecht, "Biochemistry, Biology, and Carcinogenicity of Tobacco-Specific N-Nitrosamines," Chemical Research in Toxicology, Vol. 11, No. 6, 1998, pp. 559-603. http://dx.doi.org/10.1021/tx980005y

[15] Y. S. Ding, L. Zhang, R. B. Jain, et al., "Levels of Tobacco-Specific Nitrosamines and Polycyclic Aromatic hydrocarbons in Mainstream Smoke from Different Tobacco Varieties," Cancer Epidemiology, Biomarkers \& Prevention, Vol. 17, 2008, pp. 3366-3371. http://dx.doi.org/10.1158/1055-9965.EPI-08-0320

[16] K. E. Anderson, G. J. Hammons, F. F. Kadlubar, et al., "Metabolic Activation of Aromatic Amines by Human Pancreas," Carcinogenesis, Vol. 18, No., 1997, pp. 10851092. http://dx.doi.org/10.1093/carcin/18.5.1085

[17] P. Chowdhury and P. L. Rayford, "Smoking and Pancreatic Disorders," European Journal of Gastroenterology \& Hepatology, Vol. 12, 2000, pp. 869-877. http://dx.doi.org/10.1097/00042737-200012080-00006

[18] J. C. Mwenifumbo and R. F. Tyndale, "Molecular Genetics of Nicotine Metabolism," Handbook of Experimental Pharmacology, Vol. 192, 2009, pp. 235-259.

[19] P. Chowdhury, S. MacLeod, K. B. Udupa, et al., "Patho- physiological Effects of Nicotine on the Pancreas: An Update," Experimental Biology and Medicine, Vol. 227, No. 7, 2002, pp. 445-454.

[20] P. Chowdhury, R. Doi, L. W. Chang, et al., "Tissue Distribution of [3H]-Nicotine in Rats," Biomedical and Environmental Sciences, Vol. 6, No. 1, 1993, pp. 59-64.

[21] B. Prokopczyk, D. Hoffmann, M. Bologna, et al., "Identification of Tobacco-Derived Compounds in Human Pancreatic Juice," Chemical Research in Toxicology, Vol. 15, No. 5, 2002, pp. 677-685. http://dx.doi.org/10.1021/tx0101088

[22] P. Chowdhury, R. Hosotani, L. Chang, et al., "Metabolic and Pathologic Effects of Nicotine on Gastrointestinal Tract and Pancreas of Rats," Pancreas, Vol. 5, 1990, pp. 222-229. http://dx.doi.org/10.1097/00006676-199003000-00016

[23] P. Chowdhury, P. L. Rayford and L. W. Chang, "Induction of Pancreatic Acinar Pathology via Inhalation of Nicotine," Proceedings of the Society for Experimental Biology and Medicine, Vol. 201, No. 2, 1992, pp. 159164. http://dx.doi.org/10.3181/00379727-201-43494B

[24] P. Chowdhury, R. Hosotani and P. L. Rayford, "Inhibition of CCK or Carbachol-Stimulated Amylase Release by Nicotine," Life Sciences, Vol. 45, No. 22, 1989, pp. 2163-2168.

http://dx.doi.org/10.1016/0024-3205(89)90083-0

[25] P. Chowdhury, P. L. Rayford and L. W. Chang, "Pathophysiological Effects of Nicotine on the Pancreas," Proceedings of the Society for Experimental Biology and Medicine, Vol. 218, No. 3, 1998, pp. 168-173.

http://dx.doi.org/10.3181/00379727-218-44284

[26] B. Lindkvist, N. Wierup, F. Sundler, et al., "Long-Term Nicotine Exposure Causes Increased Concentrations of Trypsinogens and Amylase in Pancreatic Extracts in the Rat," Pancreas, Vol. 37, 2008, pp. 288-294. http://dx.doi.org/10.1097/MPA.0b013e31816a7744

[27] P. Chowdhury, C. Bose and K. B. Udupa, "NicotineInduced Proliferation of Isolated Rat Pancreatic Acinar Cells: Effect on Cell Signalling and Function," Cell Proliferation, Vol. 40, No. 1, 2007, pp. 125-141. http://dx.doi.org/10.1111/j.1365-2184.2007.00418.x

[28] P. Chowdhury and K. B. Udupa, "Effect of Nicotine on Exocytotic Pancreatic Secretory Response: Role of Calcium Signaling," Tobacco Induced Diseases, Vol. 11, No. 1, 2013, p. 1. http://dx.doi.org/10.1186/1617-9625-11-1

[29] P. Chowdhury and A. Walker, "A Cell-Based Approach to Study Changes in the Pancreas Following Nicotine Exposure in an Animal Model of Injury," Langenbeck's Archives of Surgery, Vol. 393, No. 4, 2008, pp. 547-555. http://dx.doi.org/10.1007/s00423-007-0267-1

[30] M. Alexandre, A. K. Uduman, S. Minervini, A. Raoof, C. A. Shugrue, E. O. Akinbiyi, V. Patel, M. Shitia, T. R. Kolodecik, R. Patton, F. S. Gorelick and E. C. Thrower, "Tobacco Carcinogen 4-(Methylnitrosamino)-1-(3-Pyridyl)1-Butanone Initiates and Enhances Pancreatitis Responses," The American Journal of Physiology-Gastrointestinal and Liver Physiology, Vol. 303, 2012, pp. G696-704. http://dx.doi.org/10.1152/ajpgi.00138.2012 
[31] H. M. Schuller, P. K. Tithof, M. Williams, et al., "The Tobacco-Specific Carcinogen 4-(Methylnitrosamino)-1(3-Pyridyl)-1-Butanone is a Beta-Adrenergic Agonist and Stimulates DNA Synthesis in Lung Adenocarcinoma via Beta-Adrenergic Receptor-Mediated Release of Arachidonic Acid," Cancer Research, Vol. 59, No. 18, 1999, pp. 4510-4515.

[32] A. Chaudhuri, T. R. Kolodecik and F. S. Gorelick, "Effects of Increased Intracellular cAMP on Carbacholstimulated Zymogen Activation, Secretion, and Injury in the Pancreatic Acinar Cell," The American Journal of Physiology-Gastrointestinal and Liver Physiology, Vol. 288, 2005, pp. G235-243. http://dx.doi.org/10.1152/ajpgi.00334.2004

[33] H. Friess, S. Shrikhande, E. Riesle, et al., "Phospholipase A2 Isoforms in Acute Pancreatitis," Annals of Surgery, Vol. 233, No. 2, 2001, pp. 204-212. http://dx.doi.org/10.1097/00000658-200102000-00009

[34] L. Ulloa, "The Vagus Nerve and the Nicotinic Anti-Inflammatory Pathway," Nature Reviews Drug Discovery, Vol. 4, No. 8, 2005, pp. 673-684. http://dx.doi.org/10.1038/nrd1797

[35] H. Wang, M. Yu, M. Ochani, et al., "Nicotinic Acetylcholine Receptor Alpha7 Subunit is an Essential Regulator of Inflammation," Nature, Vol. 421, No. 6921, 2003, pp. 384-388. http://dx.doi.org/10.1038/nature01339

[36] D. J. Van Westerloo, I. A. Giebelen, S. Florquin, M. J. Bruno, G. J. Larosa, L. Ulloa, K. J. Tracey and T. van der Poll, "The Vagus Nerve and Nicotinic Receptors Modulate Experimental Pancreatitis Severity in Mice," Gastroenterology, Vol. 130, No. 6, 2006, pp. 1822-1830. http://dx.doi.org/10.1053/j.gastro.2006.02.022

[37] J. B. Greer and D. C. Whitcomb, "Inflammation and Pancreatic Cancer: An Evidence Based Review," Current Opinion in Pharmacology, Vol. 9, No. 4, 2009, pp. 411-418. http://dx.doi.org/10.1016/j.coph.2009.06.011

[38] A. B. Lowenfels and P. Maisonneuve, "Environmental Factors and Risk of Pancreatic Cancer," Pancreatology, Vol. 3, No. 1, 2003, pp. 1-8. http://dx.doi.org/10.1159/000069140

[39] S. Raimondi, P. Maisonneuve, J. M. Löhr and A. B. Lowenfels, "Early Onset Pancreatic Cancer: Evidence of a Major Role for Smoking and Genetic Factors," Cancer Epidemiology Biomarks \& Prevention, Vol. 16, No. 9, 2007, pp. 1894-1897.

[40] A. S. Whittemore, R. S. Paffenbarger Jr., K. Anderson and J. Halpern, "Early Precursors of Pancreatic Cancer in College Men," Journal of Chronic Diseases, Vol. 36, No. 3, 1983, pp. 251-256. http://dx.doi.org/10.1016/0021-9681(83)90059-0

[41] S. Iodice, S. Gandini, P. Maisonneuve and A. B. Lowenfels, "Tobacco and the Risk of Pancreatic Cancer: A Review and Meta-Analysis," Langenbeck's Archives of Surgery, Vol. 393, No. 4, 2008, pp. 535-545. http://dx.doi.org/10.1007/s00423-007-0266-2

[42] T. M. Mack, M. C. Yu, R. Hanisch and B. E. Henderson, "Pancreas Cancer and Smoking, Beverage Consumption, and Past Medical History," Journal of National Cancer Institute, Vol. 76, No. 1, 1986, pp. 49-60.
[43] P. Maisonneuve and A. B. Lowenfels, "Epidemiology of Pancreatic Cancer: An Update," Digestive Disease, Vol. 28, No. 4-5, 2010, pp. 645-656. http://dx.doi.org/10.1159/000320068

[44] M. A. Anderson, E. Zolotarevsky, K. L. Cooper, S. Sherman, O. Shats, D. C. Whitcomb, H. T. Lynch, P. Ghiorzo, W. S. Rubinstein, K. J. Vogel, A. R. Sasson, W. E. Grizzle, M. A. Ketcham, S. Y. Lee, D. Normolle, C. M. Plonka, A. N. Mertens, R. C. Tripon and R. E. Brand, "Alcohol and Tobacco Lower the Age of Presentation in Sporadic Pancreatic Cancer in a Dose-Dependent Manner: A Multicenter Study," American Journal of Gastroenterology, Vol. 107, No. 11, 2012, pp. 1730-1739. http://dx.doi.org/10.1038/ajg.2012.288

[45] M. Porta, M. Crous-Bou, P. A. Wark, P. Vineis, F. X. Real, N. Malats and E. Kampman, "Cigarette Smoking and K-Ras Mutations in Pancreas, Lung and Colorectal Adenocarcinomas: Etiopathogenic Similarities, Differences and Paradoxes," Mutation Research, Vol. 682, No. 2-3, 2009, pp. 83-93. http://dx.doi.org/10.1016/j.mrrev.2009.07.003

[46] A. Blackford, G. Parmigiani, T. W. Kensler, et al., "Genetic Mutations Associated with Cigarette Smoking in Pancreatic Cancer," Cancer Research, Vol. 69, No. 8, 2009, pp. 3681-3688. http://dx.doi.org/10.1158/0008-5472.CAN-09-0015

[47] D. L. Weddle, P. Tithoff, M. Williams and H. M. Schuller, "Beta-Adrenergic Growth Regulation of Human Cancer Cell Lines Derived from Pancreatic Ductal Carcinomas," Carcinogenesis, Vol. 22, No. 3, 2001, pp. 473-479. http://dx.doi.org/10.1093/carcin/22.3.473

[48] M. D. Askari, M. S. Tsao and H. M. Schuller, "The Tobacco-Specific Carcinogen, 4-(methylnitrosamino)-1-(3pyridyl)-1-Butanone Stimulates Proliferation of Immortalized Human Pancreatic Duct Epithelia through BetaAdrenergic Transactivation of EGF Receptors," Journal of Cancer Research and Clinical Oncology, Vol. 131, No. 10, 2005, pp. 639-648.

http://dx.doi.org/10.1007/s00432-005-0002-7

[49] H. Yoshikawa, E. Hellström-Lindahl and V. Grill, "Evidence for Functional Nicotinic Receptors on Pancreatic Beta Cells," Metabolism, Vol. 54, No. 2, 2005, pp. 247254. http://dx.doi.org/10.1016/j.metabol.2004.08.020

[50] C. H. Park, I. S. Lee, P. Grippo, S. J. Pandol, A. S. Gukovskaya and M. Edderkaoui, "Akt Kinase Mediates the Prosurvival Effect of Smoking Compounds in Pancreatic Ductal Cells," Pancreas, Vol. 42, No. 4, 2013, pp. 655662. http://dx.doi.org/10.1097/MPA.0b013e3182762928

[51] P. Dasgupta, W. Rizwani, S. Pillai, R. Kinkade, M. Kovacs, S. Rastogi, S. Banerjee, M. Carless, E. Kim, D. Coppola, E. Haura and S. Chellappan, "Nicotine Induces Cell Proliferation, Invasion and Epithelial-Mesenchymal Transition in a Variety of Human Cancer Cell Lines," International Journal of Cancer, Vol. 124, No. 1, 2009, pp. 36-45. http://dx.doi.org/10.1002/ijc.23894

[52] J. G. Trevino, S. Pillai, S. Kunigal, S. Singh, W. J. Fulp, B. A. Centeno and S. P. Chellappan, "Nicotine Induces Inhibitor of Differentiation-1 in a Src-Dependent Pathway Promoting Metastasis and Chemoresistance in Pancreatic 
Adenocarcinoma," Neoplasia, Vol. 14, No. 12, 2012, pp. 1102-1114.

[53] M. Alexandre, S. J. Pandol, F. S. Gorelick and E. C. Thrower, "The Emerging Role of Smoking in the Development of Pancreatitis," Pancreatology, Vol. 11, No. 5, 2011, pp. 469-474. http://dx.doi.org/10.1159/000332196

[54] M. A. Dubick, R. Palmer, P. P. Lau, P. R. Morrill and M. C. Geokas, "Altered Exocrine Pancreatic Function in Rats Treated with Nicotine," Toxicology and Applied Pharmacology, Vol. 96, No. 1, 1988, pp. 132-139. http://dx.doi.org/10.1016/0041-008X(88)90255-4

[55] P. P. Lau, M. A. Dubick, G. S. Yu, P. R. Morrill and M. C. Geokas, "Dynamic Changes of Pancreatic Structure and Function in Rats Treated Chronically with Nicotine," Toxicology and Applied Pharmacology, Vol. 104, No. 3, 1990, pp. 457-465. http://dx.doi.org/10.1016/0041-008X(90)90167-S

[56] M. Edderkaoui, P. Hong, E. C. Vaquero, J. K. Lee, L. Fischer, H. Friess, M. W. Buchler, M. M. Lerch, S. J. Pandol and A. S. Gukovskaya, "Extracellular Matrix Stimulates Reactive Oxygen Species Production and Increases Pancreatic Cancer Cell Survival through 5-Lipoxygenase and NADPH Oxidase," American Journal of Physiology. Gastrointestinal and Liver Physiology, Vol. 289, No. 6, 2005, pp. G1137-G1147. http://dx.doi.org/10.1152/ajpgi.00197.2005

[57] I. Esposito, M. Menicagli, N. Funel, F. Bergmann, U. Boggi, F. Mosca, G. Bevilacqua and D. Campani, "Inflammatory Cells Contribute to the Generation of an Angiogenic Phenotype in Pancreatic Ductal Adenocarcinoma," Journal of Clinical Pathology, Vol. 57, No. 6, 2004, pp. 630636. http://dx.doi.org/10.1136/jcp.2003.014498

[58] B. Philip, C. L. Roland, J. Daniluk, Y. Liu, D. Chatterjee, S. B. Gomez, B. Ji, H. J. Huang, H. M. Wang, J. B. Fleming, C. D. Logsdon and Z. Cruz-Monserrate, "A High-Fat Diet Activates Oncogenic Kras and COX2 to Induce Development of Pancreatic Ductal Adenocarcinoma in Mice," Gastroenterology, 2013. (in press)

[59] N. Momi, M. P. Ponnusamy, S. Kaur, S. Rachagani, S. S. Kunigal, S. Chellappan, M. M. Ouellette and S. K. Batra, "Nicotine/Cigarette Smoke Promotes Metastasis of Pancreatic Cancer through $\alpha 7 \mathrm{nAChR}$-mediated MUC4 Upregulation," Oncogene, Vol. 32, No. 11, 2013, pp. 1384-1395. http://dx.doi.org/10.1038/onc.2012.163

[60] I. G. Nicolov and I. N. Chernozemsky, "Tumors and hyperplastic lesions in Syrian Hamsters Following Transplacental and Neonatal Treatment with Cigarette Smoke Condensate," Journal of Cancer Research and Clinical Oncology, Vol. 94, No. 3, 1979, pp. 249-256. 